\title{
Power Harvesting Wireless Sensor from Ambient Microwaves for Mobile Charging
}

\author{
Steffi Jose \\ MTech Scholar, Department of ECE \\ MZCE Kadammanitta, Pathanamthitta, Kerala, India
}

\begin{abstract}
This paper describes power harvesting for mobile charging from ambient microwaves. Battery life of mobile phone is always been a problem for manufacturers. People are complaining about their mobile's battery life,that they don't have long battery life and they have to charge their phone several times. Portable electronic devices are very popular now a days. As the usage of these portable electronic devices is increasing, the demands for longer battery life are also increasing. This wireless battery charger is expected to eliminate all the hassles with today's battery technology. In this paper a new proposal has beenmade so as to make the recharging of the mobile phones is done automatically as you talk in your mobile phone! This is done by use of microwaves. There are minimal additions, which have to be made in the mobile handsets, which are the addition of a sensor, a "rectenna" and a filter. With the above setup, the need for separate chargers for mobile phones is eliminated and makes charging universal. Thus the more you talk, the mobile phones is eliminated and makes charging universal. Thus the more you talk, the more is your mobile phone charged.
\end{abstract}

Keywords: Band pass filter, Global for mobile communications Industrial, scientific and medical ,International telecommunication union, Slotted waveguide antenna

\section{INTRODUCTION}

Energy is the major acquaintance a person can have these put other coil over there than it is induce by the first coil days. . And nearly everyone has a cellular phone, whether and it carry current from it. This is the principle of it's for business purpose or personal use. You need an magnetic induction. The electromagnetic spectrum is the efficient way of charging the battery ofyour phone range of all possible frequencies of electromagnetic anytime, anywhere and at any cost. Electromagnetic (EM) radiation. The electromagnetic spectrum extends from radiation is a self-propagating wave in space with electric below the low frequencies used for modern radio and magnetic components. One important type of communication to gamma radiation at the shortelectromagnetic radiation on basis of frequency is wavelength (high-frequency) end.

"Microwaves" with frequency range of $300 \mathrm{MHz}$ to $300 \mathrm{GHz}$. Microwave technology is extensively used for point-to-point telecommunications (i.e., non-broadcast uses). Microwaves are especially suitable for this use since they are more easily focused into narrow beams than radio waves, allowing frequency reuse; their comparatively higher frequencies allow broad bandwidth and high data transmission rates, and antenna sizes are smaller than at lower frequencies because antenna size is inversely proportional to transmitted frequency. Microwaves are used in spacecraft communication, and much of the world's data, TV, and telephone communications are transmitted long distances by microwaves between ground stations and communications satellites. Microwaves are also employed in microwave ovens and in radar technology. The microwave signal is transmitted from the transmitter along with the message signal using special kind of antennas called slotted wave guide antenna at a frequency is $2.45 \mathrm{GHz}$. There are minimal additions, which have to be made in the mobile handsets, which are the addition of a sensor, a "rectenna" and a filter.

\section{FUNCTIONING}

Wireless power transmission works on the principle of magnetic induction. As we put one coil carrying current through it, it creates a magnetic field near to it. And if we

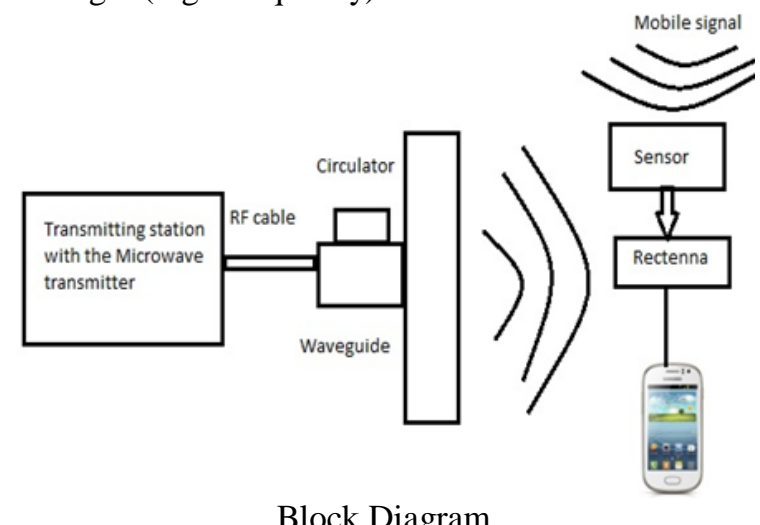

They consist of two part. One is transmitting part and the other is the Receiving part. At the transmitting end there is one microwave power source which is actually producing microwaves. Which is attach to the Coax-Waveguide and here Tuner is the one which match the impedance of the transmitting antenna and the microwave source. Directional Coupler helps the signal to propagate in a particular direction. Receiver side Impedance matching circuit receives the microwave signal through Rectena circuit. This circuit is nothing but the combination of filter circuit and the schottky Diode. Which actually convert our microwave in to the DC power. 


\section{International Journal of Advanced Research in Computer and Communication Engineering} Vol. 4, Issue 2, February 2015

\section{III.TranSMITTER DESIGN}

A.

Magnetron is the combination of a simple diode vacuum tube with built in cavity resonators and an extremely powerful permanent magnet. The typical magnet consists of a circular anode into which has been machined with an even number of resonant cavities. The diameter of each cavity is equal to a one-half wavelength at the desired operating frequency.

\section{B. SLOTTED WAVEGUIDE ANTENNA}

The slotted waveguide is used in an omni-directional role. It is the simplest ways to get a real $10 \mathrm{~dB}$ gain over 360 degrees of beam width. The Slotted waveguide antenna is a Horizontally Polarized type Antenna, light in weight and weather proof. 3 Tuning screws are placed for tweaking the SWR and can be used to adjust the center frequency downwards from $2320 \mathrm{MHz}$ nominal to about $2300 \mathrm{MHz}$. This antenna is available for different frequencies. This antenna, called a slotted waveguide, is a very low loss transmission line. It allows propagating signals to a number of smaller antennas (slots).

\section{IV.RECIEVER DESIGN}

\section{A. RECTENNA}

A rectifying antenna rectifies received microwaves into DC current. A rectenna comprises of a mesh of dipoles and diodes for absorbing microwave energy from a transmitter and converting it into electric power. A simple rectenna can be constructed from a Schottky diode placed between antenna dipoles. The diode rectifies the current induced in the antenna by the microwaves. Rectenna are highly efficient at converting microwave energy to electricity

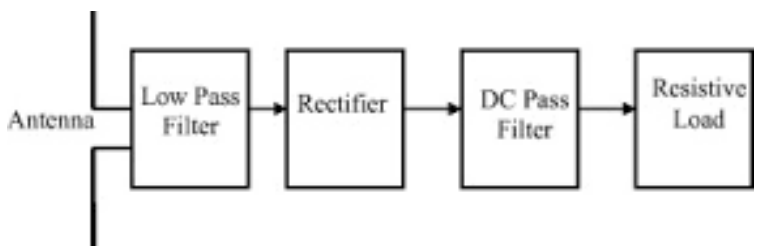

There are at least two advantages for rectennas:

1. The life time of the rectenna is almost unlimited and it does not need replacement (unlike batteries).

2. It is "green" for the environment (unlike batteries, no deposition to pollute the environment)

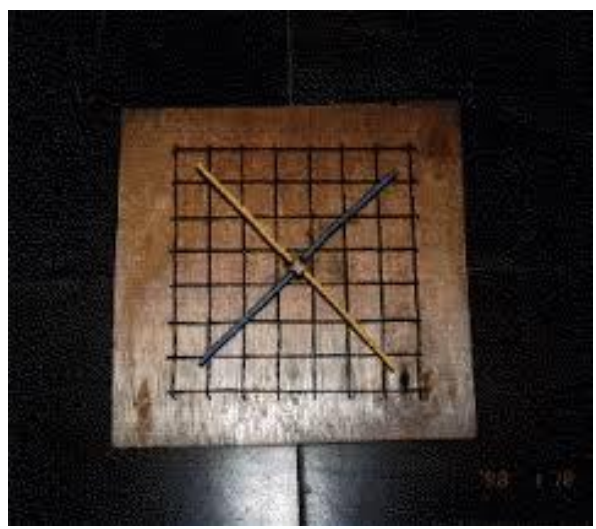

\section{B .SCHOTTKY BARRIER DIODE}

A Schottky barrier diode is different from a common $\mathrm{P} / \mathrm{N}$ silicon diode. The common diode is formed by connecting a $\mathrm{P}$ type semiconductor with an $\mathrm{N}$ type semiconductor, this is connecting between a semiconductor and another semiconductor; however, a Schottky barrier diode is formed by connecting a metal with a semiconductor. When the metal contacts the semiconductor, there will be a layer of potential barrier (Schottky barrier) formed on the contact surface of them, which shows a characteristic of rectification.

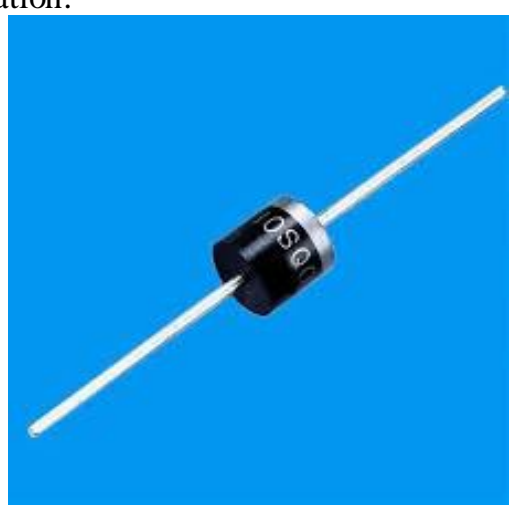

\section{C.SENSOR CIRCUITRY}

The sensor circuitry is a simple circuit, which detects if the mobile phone receives any message signal. This is required, as the phone has to be charged as long as the user is talking. Thus a simple $\mathrm{F}$ to $\mathrm{V}$ converter would serve our purpose. In India the operating frequency of the mobile phone operators is generally $900 \mathrm{MHz}$ or $1800 \mathrm{MHz}$ for the GSM system for mobile communication.

\section{PROCESS OF RECTIFICATION}

Studies on various microwave power rectifier configurations show that a bridge configuration is better than a single diode one. But the dimensions and the cost of that kind of solution do not meet our objective. This study consists in designing and simulating a single diode power rectifier in "hybrid technology" with improved sensitivity at low power levels. Microwave energy transmitted from space to earth

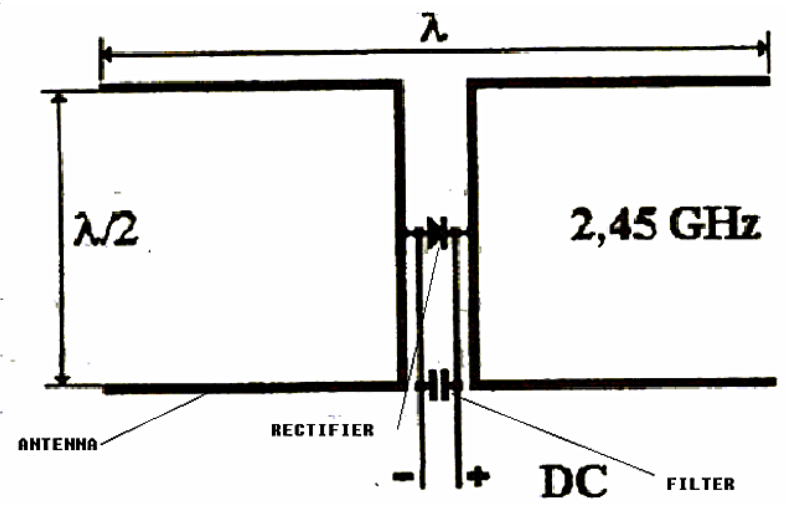

The aim of this study is to make a low cost power rectifier for low and high power levels at a frequency of $2.45 \mathrm{GHz}$ with good efficiency of rectifying operation. The objective also is to increase the detection sensitivity at low power levels of power. 


\section{Advantages}

1. Charging of mobile phone is done wirelessly

2. We can saving time for charging mobiles

3. Wastage of power is less

4. Mobile get charged as we make call even during long journey

5. Only one microwave transmitter can serve to all the service providers in that area

\section{VI.APPLICATION}

Wireless charging of mobile phones using microwaves

\section{FUTURE SCOPE}

1. In future RECTENNA is used to produce large-scale power from microwaves beam

2. This technology is also applicable for electronic gadgets which work on batteries and thus saves electricity.

3. Currently researches are going on to implement this technology for laptops.

\section{CONCLUSION}

This paper successfully demonstrates a novel method of using the power of the microwave to charge the mobile phones without the use of wired chargers. The main advantage of this technique is this that the mobile phone users to carry their phones anywhere even if the place is devoid of fa-cilities for charging.

\section{REFERENCES}

[1] A Wireless Battery Charger Architecture for Consumer Electronics2012 IEEE Second International Conference on Consumer Electronics -Berlin (ICCE-Berlin)

[2] ]A. P. Sample, D. T. Meyer, and 1. R. Smith, "Analysis, experimental results, and range adaptation of magnetically coupled resonators for wireless power transfer," IEEE Transactions on Industrial Electronics, pp. 544.554, 20 I I

[3] L.Chen, S.Liu, Y.Zhou and T.Cui, "An Optimizable Circuit Structure for High-Efficiency Wireless Power Transfer", IEEE Transactions on Industrial Electronics, vol.27, issue 99, November 2011, Page(s):1-10.

[4 ] H. Zhai, H. K. Pan, and M. Lu, "A practical wireless charging system based on ultra-wideband retroreflective beamforming," presented at IEEE International Symposium on Antennas and Propagation, Toronto,Canada, July 2010.

[5] A Novel Wireless Charging System for Movable Telephone with Printed-circuit-board Windings of Different Structure and Shape Respectively- Proceeding of International Conference on Electrical Machines and Systems 2007, October 8-11, Seoul, Korea, 1285.

[6] L. Chiu, T. Y. Yum, W. S. Chang, Q. Xue, and C. H. Chan, "Retrodirective array for RFID and microwave tracking beacon applications," Microwave and Optical Technology Letters, vol. 48, no. 2, pp. 409-411, February 2006.

[7] CableIess Battery Charger Using Induction Technique-Student Conference on Research and Development (SCORED) 2003 Proceedings, Putrajaya, Malaysia

[8] Hawkins, Joe, et al, "Wireless Space Power Experiment," in Proceedings of the 9th summer Conference of NASA/USRA Advanced Design Program and Advanced Space Design Program, June 14- 18, 1993.

[9] Tae-Whan yoo and Kai Chang, "Theoretical and Experimental Development of 10 and $35 \mathrm{GHz}$ rectennas" IEEE Transaction on microwave Theory and Techniques, vol.

40.NO.6.June.1992.

\section{BIOGRAPHY}

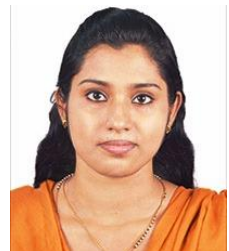

Miss Steffi Jose is a student of M.Tech (First year) communication engineering, Department of Electronics \& Communication Engineering at Mountzion College Of Engineering And Technology Kadammanitta Kerala. She completed BE in MAR Ephraem College Of Engineering And Technology Tamil Nadu.This is her first paper published here. Her area of interest is Wireless Communication. 